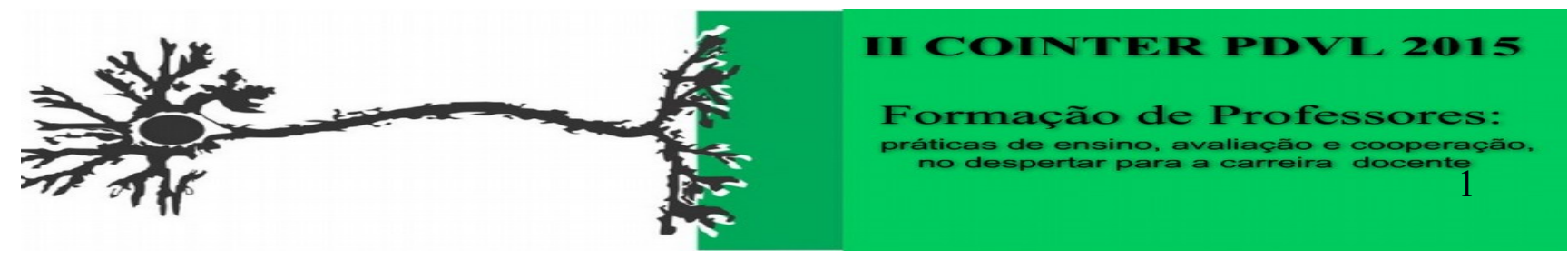

\title{
DESAFIOS E OPORTUNIDADES NA FORMAÇÃO DE EXTENSIONISTAS, A EAD COMO VEÍCULO DE APROXIMAÇÃO ENTRE GRADUANDOS, SERVIDORES E A COMUNIDADE EXTERNA NUMA PERSPECTIVA DE FORMAÇÃO DE REDES DE COOPERAÇÃO.
}

\author{
Apresentação: Comunicação Oral
}

Rosimeire Rayanne Tenório Amorim ; Gabriel Soares Juvino; Maria José Cavalcante Silva; Kilma da Silva Lima Viana; Edísio Raimundo Silva; Erick Viana da Silva

\section{Resumo}

Este trabalho tem como objetivo descrever e analisar a experiência dos cursos de formação continuada, na modalidade Ensino a Distância (EaD) do Programa Despertando Vocações (PDV) no âmbito da cooperação interinstitucional. A pesquisa é de natureza aplicada, através de um estudo de caso com abordagem qualitativa e utilizou procedimentos de pesquisa bibliográfica e documental. Como resultados verificamos que os cursos de extensão internacionais do PDV propiciaram na sua construção a superação de obstáculos de ordem burocrática, política institucional e cultural, com uma formação de redes de cooperação nas práticas extensionistas analisadas que envolveram atores de 04 países, 22 instituições e possibilitou a oferta de 1380 vagas em cursos de extensão internacionais. Potencializaram a utilização dos recursos e provocaram ações sinérgicas com benefícios para todos os atores envolvidos. Outra característica denotada foi o empoderamento de servidores, estudantes e comunidades envolvidas com pouca intervenção junto aos protagonistas por parte de agentes políticos e de gestão institucional, corroborando para uma prática inovadora de fazer extensão internacional, a baixo custo e partindo das necessidades percebidas pela comunidade de construção de soluções inovadoras.

Palavras-Chave: Formação continuada; Extensão; Internacionalização; Cooperação; Rede.

\section{Introdução}

A pesquisa terá como locus uma Autarquia, Instituto Federal de Educação Ciência e Tecnologia de Pernambuco, Instituição de Ensino Pública mantida e administrada pelo 
Governo brasileiro através do Ministério da Educação, (IF) e que por força de lei mudou sua configuração organizacional, através da fusão de duas instituições distintas já existentes e incorporou além das atividades de ensino técnico profissionalizante, competências e prerrogativas, antes, exclusivas das Universidades em relação à Pesquisa, Extensão e Inovação (BRASIL,2008)

Os Institutos Federais têm, nos últimos anos mais intensamente, percorrido trajetórias na execução das políticas de internacionalização que envolve transversalmente toda a comunidade acadêmica (FORINTER,2009). O estudo da teoria organizacional permite a análise dos resultados empíricos encontrados em comparação com as propostas de entendimento da realidade organizacional já existentes. No nosso caso, em particular, por meio da compreensão do que ocorre na metamorfose organizacional e suas tendências isomórficas de comportamento. (Di Maggio e Powell,1983) A gestão ao observar estes elementos pode estabelecer estratégias de sensibilização, identificação de recursos que possam corroborar com a condução do processo e estabelecer estratégias para tal fim. O tema internacionalização tornou-se ponto de pauta em praticamente todas as instituições, principalmente depois do Programa Ciências sem Fronteiras. No entanto, o processo de internacionalização de uma instituição não se encerra na mobilidade internacional, essa é apenas uma das facetas. Para além de um movimento de cima para baixo, atravessa a instituição e deve alcançar os diversos níveis organizacionais. Os valores, princípios, normas, tradições, enfim a cultura organizacional poderão passar por ajustes e tensionamentos até que se incorporem a nova dinâmica de ser organizacional através da institucionalização de novos valores, princípios, normas e tradições proveniente de novas interações objetivas e também subliminares de caráter informal mas não menos importante.

\section{Fundamentação Teórica}

A proposta de constituição de um Programa de Internacionalização baseado no formato de rede de cooperação passa por uma política de organização e gestão do conhecimento que precisa coincidir com as mudanças que vêm ocorrendo no ambiente interno e externo à organização, como também com a instalação de novas políticas públicas.

Estas, no Governo atual, redirecionam suas prioridades para a área social e estabelecem metas rigorosas de cumprimento do orçamento fiscal e prestação de contas aos cidadãos, influenciando diretamente os órgãos públicos por exigir um reposicionamento estratégico atrelado a uma profunda mudança no modelo de gestão da organização. 
As mudanças organizacionais, normalmente são recebidas pelos participantes com reticências, desconfianças e muitas vezes resistências devido ao alto nível de incertezas que carregam consigo. Dessa forma o Programa Internacional de Gestão e Cooperação Despertando Vocações (PDV) surge como uma proposta alternativa para a construção de novas realidades que aproveitem o capital humano. Pode propiciar o desenvolvimento de novas competências requeridas e propiciar o alcance da missão, ou no caso do setor público, a função social da instituição. A partir de tais constatações, decidimos realizar um estudo de caso de um das ações do PDV, a fim de evidenciar elementos objetivos que possa ser explorado: as redes de cooperação no campo da extensão no âmbito dos Institutos Federais, mais especificamente o Programa Internacional Despertando Vocações. A teoria institucional, basicamente, põe no centro das discussões a legitimidade da organização e a tendência ao isomorfismo. A organização deve ser vista interagindo, contextualizando o ambiente para melhor entender as tomadas de decisões. No entanto, as organizações agem dentro do contexto nos quais estão inseridas modelando-os também. Essa corrente multilateral de interações, envolvendo valores, crenças, mitos, ética leva à necessidade de agregar aos valores econômicos, de recursos humanos e logísticos, valores culturais. (SILVA,2013)

O Programa de Extensão Internacional Despertando Vocações para as Licenciaturas (PDVL) foi uma experiência piloto, inspirada em projeto semelhante destinado às carreiras das áreas tecnológicas e engenharias conduzidas pela Universidad de Mendoza (UM) e participação do Instituto Federal de Pernambuco (IFPE) no ano de 2013 e que deu prosseguimento em 2014 e 2015 conduzido por servidores do IFPE - Campus Vitória de Santo Antão. Tem o objetivo de desenvolver ações que auxiliem no despertar do interesse de estudantes do Ensino Médio para os cursos de Licenciaturas e incentivar a carreira docente dos licenciandos dessas áreas, através da articulação de atividades de ensino, pesquisa e extensão e da troca de saberes entre a Academia e a Escola Básica, utilizando-se do formato de Rede de Cooperação Internacional. Com sua execução e êxito entre os anos de 2013 a 2015 houve a ampliação de seu escopo e desdobramento de sua estrutura organizacional e de parcerias.

Dessa maneira surgiu o PDV, responsável pela formação de Redes de Cooperação e que apoia e subsidia as ações do PDVL e PDVAGRO. São compostos por dois projetos cada um: (P1), que buscam colaborar com a criação de interfaces de comunicação entre os cursos de Licenciatura/Ciências Agrárias das instituições participantes e (P2) que objetiva criar e fortalecer redes de cooperação nas áreas de ensino, pesquisa, extensão e gestão das instituições parceiras nas áreas específicas de cada PDV(Licenciaturas/Ciências Agrárias). Pretende-se, respeitando as peculiaridades de cada região e participante, gerar um fio 
condutor que possa congregar as potencialidades criativas de cada parceiro na solução de desafios comuns. No caso específico a atração e manutenção do interesse dos estudantes dos anos finais do Ensino Fundamental pelas ciências agrárias e do Ensino Médio pelas licenciaturas.

\section{Metodologia}

A pesquisa é de natureza aplicada, através de um estudo de caso único com abordagem qualitativa e utilizou nos procedimentos as pesquisas, bibliográfica. O Campo de pesquisa envolve os parceiros que interagiram na área de cursos EaD de formação dentro do PDV no período compreendido entre Setembro a Novembro de 2015.

\section{Resultados e Discussões}

Os cursos de formação continuada do PDV consistem em duas categorias distintas, os cursos presenciais e aqueles ministrados na modalidade de Ensino a Distância (EaD) com a participação de entes internacionais, neste estudo o foco encontra-se, apenas, naqueles da modalidade EaD. Os cursos são elencados e definidos preliminarmente na etapa do planejamento anual de ações com vistas a subsidiar os participantes e as comunidades atendidas de elementos teórico-práticos necessários ao alcance dos objetivos do PDV e/ou satisfação de necessidades das comunidades atendidas. Em seguida são contatados todos os possíveis parceiros interessados em ofertar e receber cursos na configuração de parceria.

Elenca-se no quadro 1 - Cursos PDV 2015, os cursos ofertados, os segmentos atendidos, instituições ministrantes e participantes, resultados obtidos.

Quadro 1- Cursos PDV 2015

\begin{tabular}{|c|c|c|c|c|c|c|}
\hline Curso & & Público & Ofertante & País/Cidade & Objetivo & Vagas \\
\hline & $\begin{array}{l}\text { Básico de } \\
\text { Empreendedori } \\
\text { smo }\end{array}$ & $\begin{array}{l}\text { Comunidad } \\
\text { e Interna e } \\
\text { Externa }\end{array}$ & $\begin{array}{l}\text { IFPE - Campus } \\
\text { Recife }\end{array}$ & Brasil-Recife & $\begin{array}{l}\text { Possibilitar ao estudante } \\
\text { condições mínimas para o } \\
\text { entendimento dos pré- } \\
\text { requisitos necessários à } \\
\text { abertura de uma negócio, } \\
\text { com a elaboração de um } \\
\text { plano de negócio. }\end{array}$ & 60 \\
\hline & $\begin{array}{ll}\text { Uso } & \mathrm{da} \\
\text { Tecnologia } & \mathrm{da} \\
\text { Informação } & \text { na }\end{array}$ & $\begin{array}{l}\text { Comunidad } \\
\text { e Interna e }\end{array}$ & $\begin{array}{lr}\text { IFSertão } & - \\
\text { Campus } & \text { Santa } \\
\text { Maria da } & \text { Boa }\end{array}$ & $\begin{array}{l}\text { Brasil - Santa } \\
\text { Maria da Boa }\end{array}$ & $\begin{array}{l}\text { Incorporar as Tecnologias da } \\
\text { Informação e Comunicação } \\
\text { (TICs) às práticas do }\end{array}$ & 60 \\
\hline
\end{tabular}




\begin{tabular}{|c|c|c|c|c|c|c|}
\hline & Extensão rural & Externa & Vista & Vista & extensionista. & \\
\hline 3. & $\begin{array}{l}\text { Organizações } \\
\text { Associativas e } \\
\text { Ação Coletiva } \\
\text { na Agricultura } \\
\text { Familiar }\end{array}$ & $\begin{array}{l}\text { Comunidad } \\
\text { e Interna e } \\
\text { Externa }\end{array}$ & $\begin{array}{l}\text { UFRPE } \\
\text { Incubacoop }\end{array}$ & Brasil-Recife & $\begin{array}{l}\text { Abordar a } \text { agricultura } \\
\text { familiar sob a perspectiva de } \\
\text { suas estratégias coletivas de } \\
\text { ação, trazendo ao } \\
\text { conhecimento dos estudantes } \\
\text { vas dimensões jurídica, } \\
\text { econômica, social, política e } \\
\text { ideológica com vista a } \\
\text { possibilitá-los } \\
\text { compreensão e capacidade } \\
\text { crítica. }\end{array}$ & 60 \\
\hline 4. & $\begin{array}{ll}\text { Coleta } & \text { de } \\
\text { Sementes } & \text { de } \\
\text { Espécies } & \\
\text { Florestais } & \end{array}$ & $\begin{array}{l}\text { Comunidad } \\
\text { e Interna e } \\
\text { Externa }\end{array}$ & $\begin{array}{l}\text { IFPE - Campus } \\
\text { Vitória }\end{array}$ & $\begin{array}{l}\text { Brasil - Vitória } \\
\text { de Santo Antão }\end{array}$ & $\begin{array}{l}\text { Propiciar aos alunos } \\
\text { conhecimentos teóricos e } \\
\text { práticos para a atividade de } \\
\text { coleta de sementes de } \\
\text { elevada qualidade em árvores } \\
\text { dos diversos portes }\end{array}$ & 60 \\
\hline 5. & $\begin{array}{l}\text { Abordagem do } \\
\text { Processo de } \\
\text { Adsorção com } \\
\text { Técnica de } \\
\text { Tratamento de } \\
\text { Água. }\end{array}$ & $\begin{array}{l}\text { Comunidad } \\
\text { e Interna e } \\
\text { Externa }\end{array}$ & $\begin{array}{l}\text { IFPB - Campus } \\
\text { João Pessoa }\end{array}$ & $\begin{array}{l}\text { Brasil - João } \\
\text { Pessoa }\end{array}$ & $\begin{array}{l}\text { Possibilitar ao estudante } \\
\text { contextualizar conteúdos de } \\
\text { química em sala de aula, } \\
\text { utilizando da temática de } \\
\text { adsorção no tratamento de } \\
\text { águas. }\end{array}$ & 60 \\
\hline 6. & $\begin{array}{l}\text { Utilização do } \\
\text { Software } \\
\text { Educacional } \\
\text { ACD/Chemisca } \\
\text { th como } \\
\text { Ferramenta no } \\
\text { Ensino de } \\
\text { Química }\end{array}$ & $\begin{array}{l}\text { Comunidad } \\
\text { e Interna e } \\
\text { Externa }\end{array}$ & $\begin{array}{l}\text { IFPE - Campus } \\
\text { Recife }\end{array}$ & Brasil - Recife & 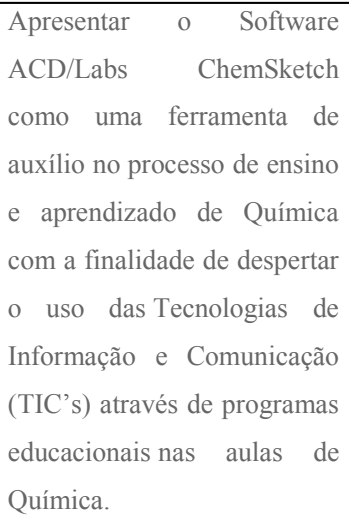 & 60 \\
\hline 7. & $\begin{array}{l}\text { Diseños } \\
\text { Curriculares } \\
\text { por } \\
\text { Competencias }\end{array}$ & $\begin{array}{l}\text { Comunidad } \\
\text { e Interna e } \\
\text { Externa }\end{array}$ & $\begin{array}{l}\text { Universidad } \\
\text { Mendoza - UM }\end{array}$ & $\begin{array}{l}\text { Argentina } \\
\text { Mendoza }\end{array}$ & $\begin{array}{l}\text { Conocer, comprender y } \\
\text { aplicar los lineamientos } \\
\text { básicos de un diseño y de un } \\
\text { desarrollo curricular por } \\
\text { competencias. Aprender a } \\
\text { trabajar en equipos de } \\
\text { profesores de la misma área o } \\
\text { de áreas distintas, en función } \\
\text { del aporte que cada una } \\
\text { realiza al perfil esperado del } \\
\text { egresado, cualquiera sea el } \\
\text { nivel. }\end{array}$ & 60 \\
\hline 8. & $\begin{array}{l}\text { Avaliação da } \\
\text { Experiência: }\end{array}$ & $\begin{array}{l}\text { Comunidad } \\
\text { e Interna e }\end{array}$ & IFPE - Campus & Brasil - Recife & $\begin{array}{lr}\begin{array}{l}\text { Conhecer e refletir sobre as } \\
\text { práticas }\end{array} & \text { avaliativas } \\
\end{array}$ & 60 \\
\hline
\end{tabular}




\begin{tabular}{|c|c|c|c|c|c|c|}
\hline & $\begin{array}{l}\text { Traçando } \\
\text { Novos } \\
\text { Cenários } \\
\text { Caminhos }\end{array}$ & Externa & Vitória & & $\begin{array}{l}\text { vivenciadas em sala de aula e } \\
\text { as relações entre essas } \\
\text { práticas, a evolução histórica } \\
\text { da avaliação, as abordagens } \\
\text { de ensino e a avaliação da } \\
\text { experiência. }\end{array}$ & \\
\hline 9. & $\begin{array}{l}\text { Inovación } \\
\text { Tecnologia y } \\
\text { Tranferencia } \\
\text { Educativa }\end{array}$ & $\begin{array}{l}\text { Comunidad } \\
\text { e Interna e } \\
\text { Externa }\end{array}$ & $\begin{array}{l}\text { Universidad } \\
\text { Tecnologica } \\
\text { Nacional -UTN }\end{array}$ & $\begin{array}{l}\text { Argentina } \\
\text { Mendoza }\end{array}$ & $\begin{array}{l}\text { Distinguir las interrelaciones } \\
\text { de la tecnología con el } \\
\text { crecimiento económico y el } \\
\text { desarrollo social desde los } \\
\text { paradigmas del desarrollo } \\
\text { contemporáneo. Valorar la } \\
\text { eficacia instrumental de } \\
\text { métodos y técnicas } \\
\text { específicas de investigación } \\
\text { usadas en el campo } \\
\text { tecnológico. Asumir el } \\
\text { protagonismo permanente } \\
\text { aprendizaje, la investigación } \\
\text { y } \\
\text { capacitación. Generar } \\
\text { acciones de articulación entre } \\
\text { niveles educativos } \\
\text { promoviendo estrategias de } \\
\text { colaboración, intercambio, } \\
\text { movilidad y enriquecimiento } \\
\text { mutuo destinadas a docentes } \\
\text { y estudiantes. }\end{array}$ & 60 \\
\hline & $\begin{array}{ll}\text { TIC } & \text { em } \\
\text { Educacion } & \end{array}$ & $\begin{array}{l}\text { Comunidad } \\
\text { e Interna e } \\
\text { Externa }\end{array}$ & $\begin{array}{l}\text { Universidad } \\
\text { Tecnologica } \\
\text { Nacional }\end{array}$ & $\begin{array}{l}\text { Argentina } \\
\text { Mendoza }\end{array}$ & $\begin{array}{l}\text { Identificar distintas } \\
\text { herramientas de las } \\
\text { tecnologías de la información } \\
\text { y la comunicación (TIC). } \\
\text { Reflexionar sobre la } \\
\text { inclusión de las herramientas } \\
\text { TIC en el aula. Aprender a } \\
\text { relevar las distintas } \\
\text { herramientas y promover su } \\
\text { inclusión tanto en educación } \\
\text { a distancia como en el } \\
\text { dictado presencial. } \\
\text { Reflexionar sobre el uso } \\
\text { responsable de las } \\
\text { herramientas informáticas en } \\
\text { el aula. }\end{array}$ & 60 \\
\hline & $\begin{array}{l}\text { Controle de } \\
\text { Qualidade na } \\
\text { Obtenção, } \\
\text { Processamento, } \\
\text { Comercializaçã } \\
\text { o e Consumo }\end{array}$ & $\begin{array}{l}\text { Comunidad } \\
\text { e Interna e } \\
\text { Externa }\end{array}$ & $\begin{array}{l}\text { IFPE - Campus } \\
\text { Vitória }\end{array}$ & $\begin{array}{l}\text { Brasil - Vitória } \\
\text { de Santo Antão }\end{array}$ & $\begin{array}{l}\text { Desenvolver a capacidade de } \\
\text { obter alimentos de origem } \\
\text { animal com segurança } \\
\text { alimentar e agregar valor à } \\
\text { matéria-prima. }\end{array}$ & 60 \\
\hline
\end{tabular}




\begin{tabular}{|c|c|c|c|c|c|c|}
\hline & $\begin{array}{l}\text { de } \text { Alimentos } \\
\text { de } \quad \text { Origem } \\
\text { Animal }\end{array}$ & & & & & \\
\hline 12. & $\begin{array}{l}\text { Uso Correcto } \\
\text { de } \\
\text { Herramientas } \\
\text { Participativas } \\
\text { Comunidade } \\
\text { Interna e } \\
\text { Externa em } \\
\text { Programas } \\
\text { Comunidade } \\
\text { Interna e } \\
\text { Externa de } \\
\text { Extensión }\end{array}$ & $\begin{array}{l}\text { Comunidad } \\
\text { e Interna e } \\
\text { Externa }\end{array}$ & MEDUCA & $\begin{array}{ll}\text { Panamá } & - \\
\text { Ciudad } & \text { de } \\
\text { Panamá } & \end{array}$ & $\begin{array}{l}\text { Desarrollar habilidades y } \\
\text { destrezas en los estudiantes } \\
\text { del nivel superior, en cuanto } \\
\text { al uso adecuado de las } \\
\text { herramientas participativas } \\
\text { en el área agropecuaria, } \\
\text { discriminar los métodos o } \\
\text { técnicas de divulgación } \\
\text { agropecuaria a emplear según } \\
\text { la situación o problema que } \\
\text { afronte nuestro (a) productor } \\
\text { (a), utilizar recursos } \\
\text { tecnológicos para la } \\
\text { implementación } \\
\text { adecuación de } \\
\text { herramientas participativas } \\
\text { de extensión agropecuaria } \\
\text { según el caso. }\end{array}$ & 60 \\
\hline 13. & $\begin{array}{l}\text { Elaboración de } \\
\text { Lombricompos } \\
t \quad \text { Para uma } \\
\text { Agricultura } \\
\text { Orgánica y } \\
\text { Sustenible }\end{array}$ & $\begin{array}{l}\text { Comunidad } \\
\text { e Interna e } \\
\text { Externa }\end{array}$ & MEDUCA & $\begin{array}{lr}\text { Panamá } & - \\
\text { Ciudad } & \text { de } \\
\text { Panamá } & \end{array}$ & $\begin{array}{l}\text { Producción de abono } \\
\text { orgánico a partir de la cría de } \\
\text { la Lombriz Roja Californian }\end{array}$ & 60 \\
\hline 14. & $\begin{array}{l}\text { Física } \\
\text { Internet: O que } \\
\text { uma coisa tem } \\
\text { haver com a } \\
\text { outra? }\end{array}$ & $\begin{array}{l}\text { Comunidad } \\
\text { e Interna e } \\
\text { Externa }\end{array}$ & $\begin{array}{l}\text { IFSertão } \\
\text { Campus } \\
\text { Salgueiro }\end{array}$ & $\begin{array}{l}\text { Brasil } \\
\text { Salgueiro }\end{array}$ & $\begin{array}{l}\text { Possibilitar ao estudante } \\
\text { construir pontes entre o } \\
\text { ensino da física e internet }\end{array}$ & 60 \\
\hline 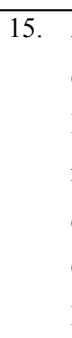 & $\begin{array}{l}\text { Argumentação } \\
\text { em Situações } \\
\text { Investigativas } \\
\text { na Construção } \\
\text { do Discurso } \\
\text { Científico na } \\
\text { Escola }\end{array}$ & $\begin{array}{l}\text { Comunidad } \\
\text { e Interna e } \\
\text { Externa }\end{array}$ & $\begin{array}{l}\text { IFPE - Campus } \\
\text { Vitória }\end{array}$ & $\begin{array}{l}\text { Brasil - Vitória } \\
\text { de Santo Antão }\end{array}$ & $\begin{array}{l}\text { Compreender } \\
\text { argumentação como recurso } \\
\text { didático na construção do } \\
\text { discurso científico na escola, } \\
\text { nos planos pragmático e } \\
\text { epistêmico }\end{array}$ & 60 \\
\hline 16. & $\begin{array}{l}\text { Caracterización } \\
\text { Del Suelo: } \\
\text { Herramienta } \\
\text { Pedagógica } \\
\text { Para El } \\
\text { Aprendizajen } \\
\text { de Las Ciencias }\end{array}$ & $\begin{array}{l}\text { Comunidad } \\
\text { e Interna e } \\
\text { Externa }\end{array}$ & $\begin{array}{l}\text { UPLA } \\
\text { Uplaced }\end{array}$ & $\begin{array}{l}\text { Chile } \\
\text { Valparaíso }\end{array}$ & $\begin{array}{l}\text { Comprender aspectos físicos } \\
\text { y químicos del suelo como } \\
\text { un elemento fundamental en } \\
\text { el sustento de la vida, con la } \\
\text { finalidad de enseñar } \\
\text { conceptos científicos, } \\
\text { medioambientales de tal } \\
\text { manera que dicha } \\
\text { caracterizaciones sean una } \\
\text { herramienta pedagógica que }\end{array}$ & 60 \\
\hline
\end{tabular}




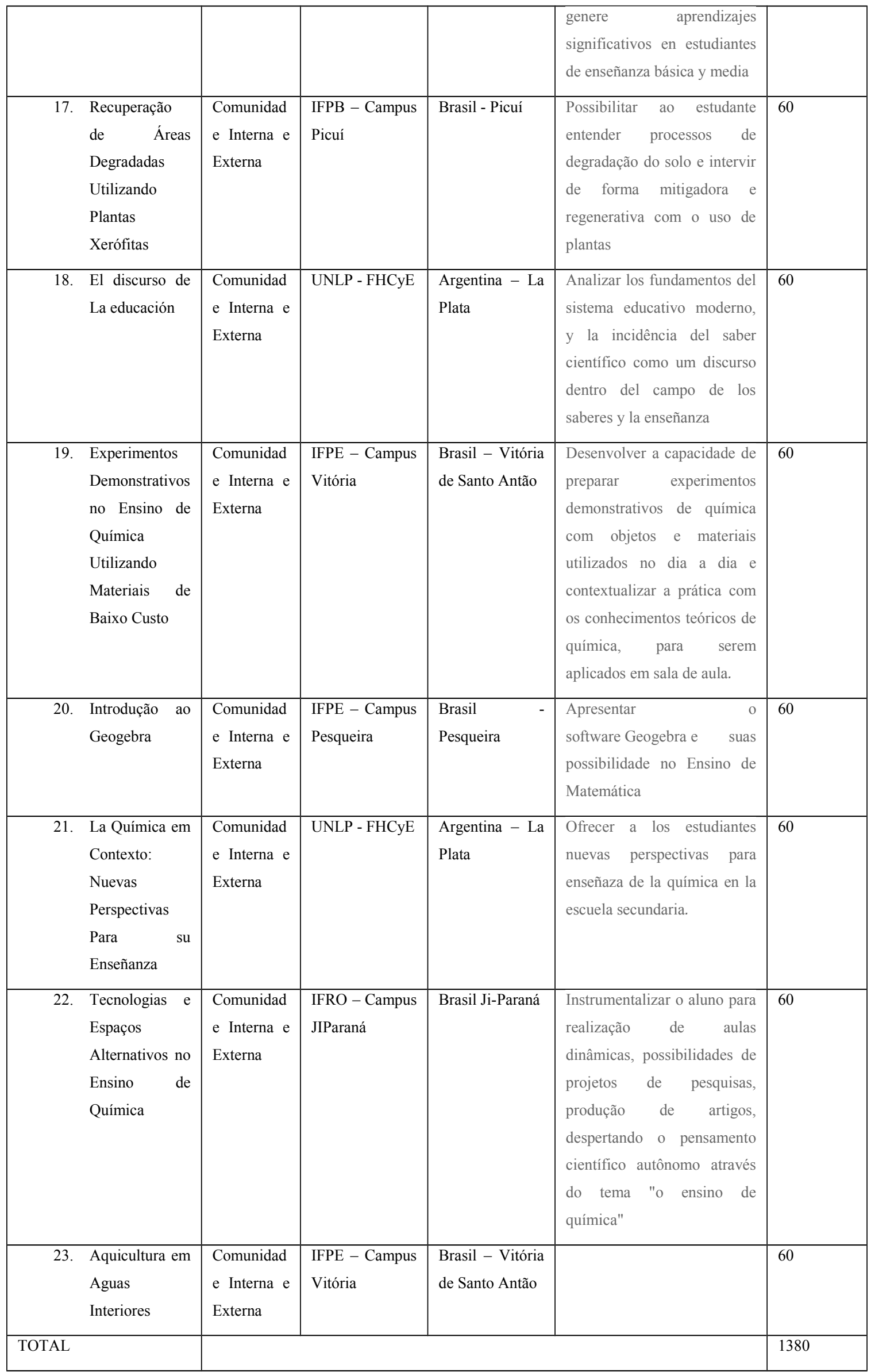


Os atores envolvidos como ministrantes dos cursos de formação EaD do PDV são servidores públicos, municipais, estaduais, federais ou da iniciativa privada que disponibilizam voluntariamente por meio de convite feito através de rede de conhecimento e confiança dos participantes. Estes, por sua vez, recebem a certificação relativa à participação no curso. Uma das preocupações do PDV se remete a perenidade do Programa diante das mudanças administrativas que podem gerar descontinuidade de trabalhos que vêm demonstrando resultados positivos. Dessa forma, o fato dos servidores realizarem as capacitações fora de seu horário de expediente, gera liberdade e independência no processo de tomadas de decisão do PDV em relação à temporariedade das gestões institucionais.

No processo de criação do ambiente virtual, inicialmente, tentou-se desenhar, construir e instalar os requisitos de hardware e software necessários ao ambiente virtual de aprendizagem (AVA) nas instituições parceiras. No entanto entraves de normatizações de acesso de segurança, limitações de pessoal para colaborar com o AVA dentro do horário de trabalho e instabilidade de sistemas provocaram na coordenação do PDV a tomada de decisão de contratar os serviços de espaço virtual e domínio ( wwww.pdvlearning.pro.br ) por conta própria. A instalação dos softwares e manutenção ficou a cargo da equipe de voluntários.

Foram selecionados estudantes voluntários dos cursos técnicos e superiores do IFPE Campus Vitória) para capacitação no AVA, designados coordenadores de área (formação de professores e ciências agrárias) e uma coordenação do AVA com responsabilidade de gerenciamento, monitoramento e controle do ambiente virtual e dos monitores dos cursos.

Paralelamente, foram elaborados materiais de divulgação, física e virtual dentre os parceiros e nas redes sociais. Foi acordado que cada ministrante de um curso de $30 \mathrm{~h}$ com 04 semanas de duração garantiria 60 vagas para sua comunidade de vinculação profissional ou a quem se interessar destinar. Os cursos foram divididos em 03 módulos de 4 semanas entre os meses de Setembro a Dezembro de 2015.

Percebeu-se durante a execução de que há necessidade de uma formação mais aprofundada dos monitores participantes das atividades para fazer frente à natural evasão que ocorre nesta modalidade. Verificou-se, concomitantemente, a melhora na elaboração das salas de aula a cada modulo e o interesse de alguns docentes em utilizar o AVA como ampliação do seu tempo pedagógico com os estudantes dos cursos regulares de suas instituições.

\section{Conclusões}


Como o PDV se encontra em andamento, as conclusões são parciais e refletem mais uma expectativa do que números e resultados precisos por si só. No entanto, no período de 06 meses desde a preparação à execução foram realizados 18 cursos na modalidade EaD e 04 estão em execução com a participação direta de participantes de 12 instituições distintas, com preparação de pessoas para atuação profissional em diversas áreas de atuação por profissionais de instituições reconhecidas nacional e internacionalmente. O que foi vivenciado até então demonstra que é possível superar as fronteiras da instituição e ir além do seu entorno, percebe-se que a extensão, atualmente, deve ser expandida globalmente, inserindo, neste contexto, entes extranacionais como colaboradores e construtores de uma perspectiva da compreensão de soluções locais baseadas em experiências globais. Observamos, assim, que é possível fazer parcerias e trabalhar em equipe, no setor público, à similaridade do que já ocorre no setor privado desde o final do século passado. É possível também inserir os extensionistas no planejamento e produção de materiais, auxiliando a formação de estudantes protagonistas, assim como, desenvolver capacidade de enfrentamento de desafios e alcance de soluções inovadoras e criativas.

\section{Referências:}

DA SILVA, Erick Viana. Globalização e Indústria Farmacêutica: para além da saúde, uma questão de mercado. CIENTEC, p. 124. Disponível em http://www.google.com.br/url? $\mathrm{sa}=\mathrm{t} \& \mathrm{rct}=\mathrm{j} \& \mathrm{q}=\& \mathrm{esrc}=\mathrm{s} \&$ source $=$ web $\& \mathrm{~cd}=1 \& \mathrm{ved}=0 \mathrm{CCwQFjAA} \& u r \mathrm{l}=\mathrm{http} \% 3 \mathrm{~A} \% 2 \mathrm{~F}$ \%2F200.133.17.83\%2Fcientec\%2Fuserfiles\%2Ffile\%2FCIENTEC $\% 25202 \% 2$ Fartigo \%252011.pdf\&ei=zVQ U9k3iKuxBK2agLgD\&usg=AFQjCNFFJPMkIXh6hedodJRTG 35g VUmmg\&bvm=bv.64125504,d.cWc Acesso em 01 de Abril de 2013.

DI MAGGIO,P.J. \& POWELL,W. " the iron cage revisited” institucional isomorphism and collective rationality in organizational fields. American Sociologycal Review.48. 147-60.1983

FORINTER, Fórum de assessores de relações internacionais, documento base. 2009.

BRASIL. Lei $n^{\circ}$ 11.892, de 29 de dezembro de 2008. Institui a Rede Federal de Educa- ção Profissional, Científica e Tecnológica, cria os Institutos Federais de Educação, Ciência e Tecnologia, e dá outras providências. Diário Oficial da União, Brasília, 30 dez. 2008, Seção 1, p. 1 . 